\title{
Jean Cruveilhier and his contributions to understanding childhood hydrocephalus, Chiari II malformation, and spina bifida
}

\author{
Michele Davis $^{1}$ - Marios Loukas ${ }^{1} \cdot$ R. Shane Tubbs ${ }^{1,2}$
}

Received: 30 June 2017 / Accepted: 6 July 2017 /Published online: 24 October 2017

(C) Springer-Verlag GmbH Germany 2017

\section{Introduction}

Jean Cruveilhier (Fig. 1) was a French anatomist and pathologist, born in Limoges, France, in 1791, [1-3] the son of a military surgeon. He studied medicine at the University of Paris, receiving his degree in 1816, under the famous anatomist Guillaume Dupuytren [2-4]. He is most well-known for his two books, a six-volume Anatomie pathologique du corps humain (1828-1842) and the Traitè d'anatomie pathologique gènèrale (1849-1864) [3, 4]. Both works are known for their illustrations and the concepts described such as phlebitis and the role of inflammation in the general disease process [2]. Cruveilhier "was essentially a researcher who owed his reputation more to his books than his teaching" [4]. He was notorious for adding extensive clinical information from each case in his books, along with the detailed illustrations, including patient histories, physical examination findings, and autopsy reports [2].

Cruveilhier held many positions throughout his career. He was selected to be an associate professor at Montpellier Faculty of Medicine in 1823 because of Dupuytren's influence. Dupuytren also created a new position of chair of pathological anatomy in 1836, to which Cruveilhier was appointed and relinquished his former position as chair of normal anatomy $[2,4]$.

During his career, he experimented and studied many different concepts and pathologies. These include experiments

R. Shane Tubbs

shanet@seattlesciencefoundation.org

1 Department of Anatomical Sciences, St. George's University, St. George's, Grenada

2 Seattle Science Foundation, Seattle, WA 98122, USA

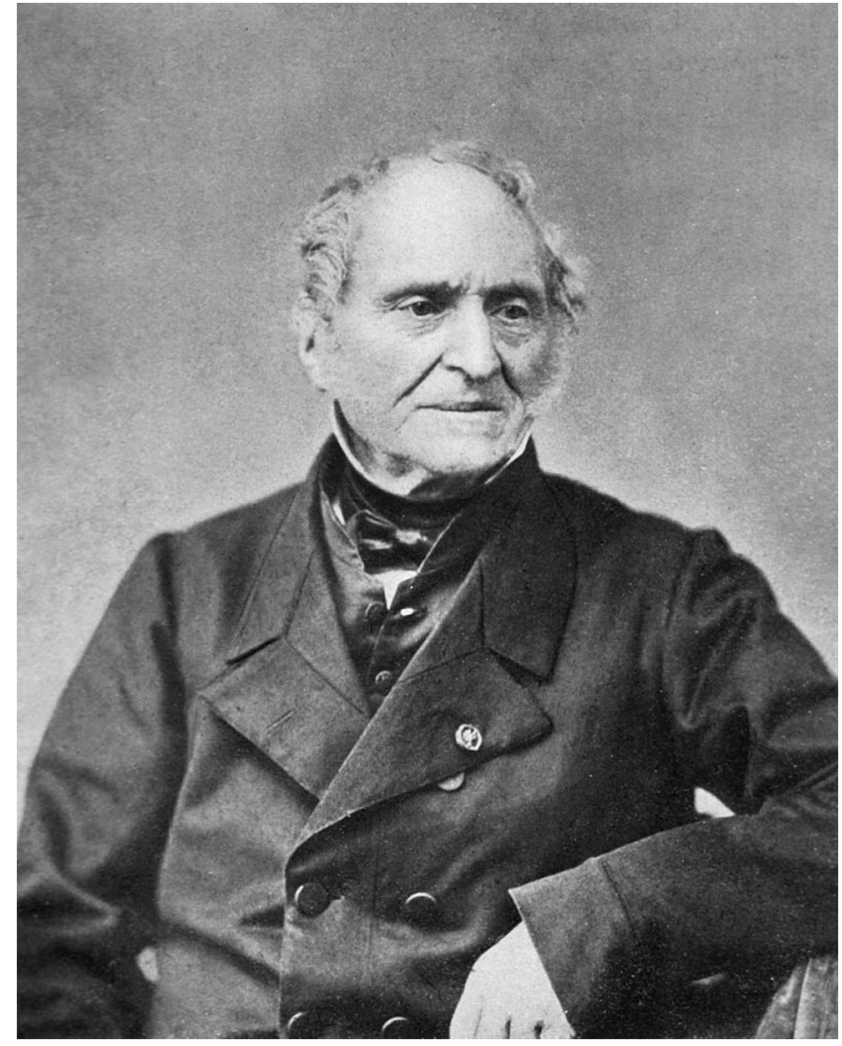

Fig. 1 Photograph of Jean Cruveilhier. Drawing from Cruveilhier's work depicting his study of a child with myelomeningocele, arachnoiditis with massive hydrocephalus

on bone fractures with callus formation in the healing process, fleshing out his theory of phlebitis by injecting mercury into blood vessels and the bronchial system, the concepts of embolism and infarction, later developed by Virchow in 1846, and naming and describing nerves in the face and head $[2,4]$.

Cruveilhier is most known for his six-volume Anatomie pathologgique du corps humain (1828-1842) and the Traitè 
d'anatomie pathologique gènèrale (1849-1864). In these works, he describes gastric ulcers, diverticulosis, progressive muscular paralysis, fibrous tissues in breast vs breast cancer, diffuse cerebral sclerosis, and the dilation of the veins in the abdominal wall, later to be known as caput medusae as described by Clemens von Baumgarten [1]. He has also described different malignancies, such as a cerebral tumor that had invaded the acoustic nerve, claiming the criteria for malignancy as "cancerous juice" [4]. Although Cruveilhier's knowledge of histology was minimal, his findings remained valid even after the use of the microscope was seen in later work [4]. His work also includes early reports of different types of cerebral atrophy among children such as microcephaly, cerebral dysgenesis, hydrocephaly, and porencephaly (Fig. 2 and cover image). These reports have colored illustrations with clinical histories of the patients [1].

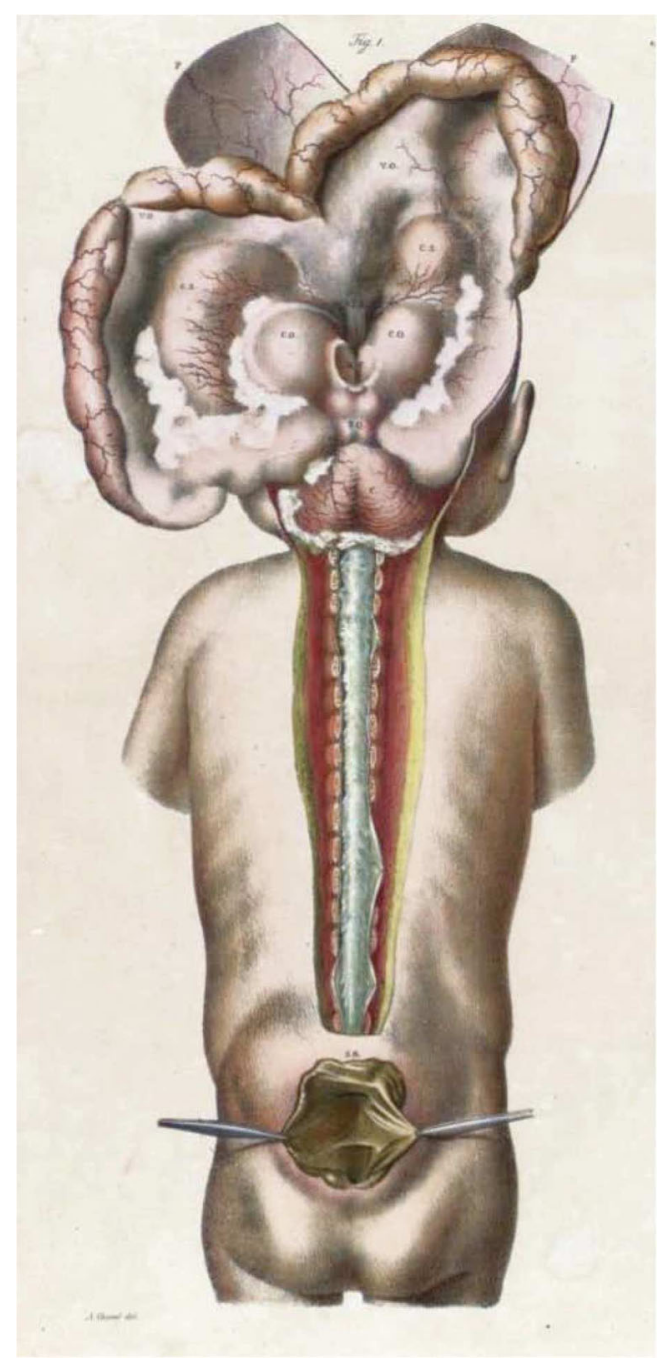

Fig. 2 and cover image Extreme hydrocephalus in a patient with spina bifida as reported by Cruveilhier

\section{Spina Bifida}

The first introduction and illustration of spina bifida was in Observationes Medicae by Dr. Nicholas Tulp in 1641, who termed the name "spina bifida" [5]. The book described six cases of patients with varieties of nerve prolongations scattered in various directions through the tumor. One patient described had a large myelomeningocele sac that Tulp dissected and illustrated after attempting to repair the myelomeningocele $[1,5]$.

Jean Cruveilhier was responsible for creating one of the finest and earliest illustrations of the different examples of spina bifida. These illustrations were hand-colored drawings and were published in a series. Case series, case presentation, and clinical findings were included in the series with thorough observations and comments as to the disease process by Cruveilhier. Four sections of the work were dedicated to spina bifida and hydrocephalus. One of his clinical presentations was a child seen initially at 3 days old and followed for the next 2 weeks until the child succumbed to meningitis [1]. Cruveilhier described his observations on autopsy revealing massive hydrocephalus leading to flattened gyri and sulci as well as purulent matter throughout the ventricles. He hypothesized the infection had spread from the spina bifida to the ventricles via the subarachnoid space coursing through the foramen of Magendie [5]. In contrast to Morgagni that believed the malformation was due to local hydrostatic pressure, Cruveilhier believed the malformation was a developmental abnormality [1].

The second case described by Cruveilhier was what is now called a Chiari type II malformation, 55 years before it was definitively described by Arnold and Chiari. In fact, some have used the term "Cruveilhier-Cleland-Chiari malformation" to describe this subset of patients with hindbrain herniation [6]. John Cleland published on spina bifida in 1883 [7]. The patient described by Cruveilhier was a child with a myelomeningocele that succumbed from sepsis secondary to meningitis. His description on autopsy revealed bony anomalies of spina bifida with the associated split cord malformation as well as the variations in the posterior cranial fossa and cerebellum that are what we now call a Chiari type II malformation. Two other cases were noted by Cruveilhier that had similar findings and he concluded spina bifida occurred secondarily to a developmental abnormality [2]. His further observations revealed the clinical cases that involved a sac covering the myelomeningocele; the child had no dangerous findings until the sac was opened. When the sac was punctured, the child would end up with one or more of the following symptoms: fever, convulsions, infections, paraplegia, sepsis, seizures, and death usually occurring in several hours to days $[2,5]$. 
Conclusions It is on the shoulders of such giants such as Jean Cruveilhier that current knowledge of spina bifida, hydrocephalus and Chiari II malformation is based.

\section{Compliance with ethical standards}

Conflict of interest The authors declare that they have no conflicts of interest.

\section{References}

1. Ashwal S (1990) The founders of child neurology. Norman Publishing, San Francisco
2. Flamm ES (1973) The neurology of Jean Cruveilhier. Med Hist 17: 343-355

3. Enersen D: Jean Cruveilhier (2017) http://www.whonamedit.com/ doctor.cfm/892.html

4. Gillispie CC, Holmes FL, Koertge N (2008) Complete dictionary of scientific biography: Cruveilhier. Jean. Charles Scribner's Sons, Detroit

5. Ozek MM, Cinalli G, Maixner WJ (2008) Spina bifida: management and outcome. Springer-Verlag, Milan

6. Pearce JMS (2000) Arnold Chiari, or "Cruveilhier Cleland Chiari" malformation. J Neurol Neurosurg Psychiatry 68:13

7. Cleland (1883) Contributions to the study of spina bifida, encephalocoele, and anencephalus. J Anat Physiol 17: 257-291 